\title{
PEMBERDAYAAN MASYARAKAT DESA MELALUI INOVASI PENGEMASAN MAKANAN DI KECAMATAN PAYARAMAN KABUPATEN OGAN ILIR, SUMATERA SELATAN
}

\author{
Oleh : \\ Rina Ratih, Hardani Dwi Jayanti, dkk \\ Universitas Ahmad Dahlan
}

\begin{abstract}
Abstrak
Salah satu permasalahan di masyarakat yang ada di Kecamatan Payaraman Kabupaten Ogan Ilir, Sumatera Selatan ialah 1) Kurangnya kreativitas masyarakat dalam hal pengemasan makanan. 2) Kurangnya pengetahuan dalam mengembangkan produk yang ada. 3) Kurangnya pengetahuan dalam hal pemasaran makanan. Padahal masyarakat mempunyai potensi untuk menghasilkan makanan khas dari bahan dasar singkong yang seharusnya bisa dipasarkan, namun masyarakat mempunyai keterbatasan pendidikan dan kreativitas dalam pengemasan makan produknya. Maka dari itu dibuat program kreativitas dalam mengemas makanan. Agar masyarakat bisa memasarkan hasil potensi desa dengan baik dan bisa menambah penghasilan. Metode yang dipakai dalam kegiatan inovasi pengemasan makanan yaitu 1) dengan mengadakan penyuluhan kewirausahaan dan 2) dengan pelatihan pengemasan makanan. Dampak program kegiatan ini adalah 1) Mampu mengangkat perekonomian desa atau kecamatan. 2) Mampu menambah pendapatan perkapita untuk setiap keluarga. 3) Meningkatkan kesejakterahan perekonomian. 4) Mampu menjualkan produk ke luar Kecamatan.
\end{abstract}

Kata Kunci: makanan, pemberdayaan

\begin{abstract}
One of the problems in society in Payaraman Sub-District, Ogan Ilir Regency, South Sumatra is 1) Lack of community creativity in food packaging. 2) Lack of knowledge in developing existing products. 3) Lack of knowledge in terms of food marketing. Though the community has the potential to produce a special food from the basic ingredients of cassava that should be marketed, but people have limited education and creativity in the packaging of food products. Thus created a program of creativity in packing food. So that people can market the results of the potential of the village well and can increase income. Methods used in food packaging innovation activities are 1) by holding entrepreneurship counseling and 2) with food packaging training. The impact of this program of activity is 1) Able to raise the village or sub-district economy. 2) Able to increase per-capita income for each family. 3) Increase the economic prosperity. 4) Able to sell products outside the District.
\end{abstract}

Keywords: food, empowermen

\section{A. PENDAHULUAN}

Payaraman adalah sebuah Kecamatan di Kabupaten Ogan Ilir, Sumatera Selatan, Indonesia. Kecamatan ini merupakan satu dari enam belas kecamatan yang ada di Kabupaten Ogan Ilir. Kecamatan Payaraman terbentuk sejak tahun 2006 berdasarkan Peraturan Daerah Kabupaten Ogan Ilir Nomor 22 Tahun 2005 yang merupakan hasil dari pemekaran Kecamatan Tanjung Batu. Kecamatan Payaraman memiliki luas wilayah administrasi 180,57 km2 atau 18.057 hektar. Jumlah penduduk Kecamatan Payaraman 
tahun 2010 mencapai 44.585 jiwa terdiri dari laki-laki berjumlah 22.358 jiwa dan perempuan berjumlah 22.227 jiwa. Pada tahun 2006 jumlah penduduk mencapai 41.192 jiwa, tahun 2007 meningkat menjadi 41.785 jiwa, pada tahun 2008 menjadi 43.591 jiwa dan pada tahun 2009 meningkat menjadi 44.301 jiwa. Kepadatan penduduk tahun 2010 mencapai 440 jiwa per km2 dan jumlah kepala keluarga sebanyak 11.342 KK.

Pendampingan social hadir sebagai agen of change yang terlibat dalam membantu pemecahan masalah yang dihadapi masyarakat. Pendampigan masyarakat dapat diartikan sebagai interaksi dinamis antara kelompok masyarakat secara bersama-sama menghadapi tantangan seperti program kehidupan sosial ekonomi, menciptkan akses kerjasama dengan berbagai pihak yang baik untuk menunjang masyarakat yang sejahtera.

Merujuk pada Payne (1986), prinsip utama pendampingan adalah "making the best of the client's resources".Sejalan dengan perspektif kekuatan (strengths perspektif), para pendamping masyarakat tidak memandang klien dan lingkungannya sebagai sistem yang pasif dan tidak memiliki potensi apa-apa. Melainkan mereka dipandang sebagai sistem sosial yang memiliki kekuatan positif dan bermanfaat bagi proses pemecahan masalah.

Desa adalah perwujudan geografis yang ditimbulkan oleh unsur-unsur fisiografis, sosial, ekonomis politik, kultural setempat dalam hubungan dan pengaruh timbal balik dengan daerah lain. Desa merupakan kesatuan hukum tempat tinggal suatu masyarakat yang berhak menyelenggarakan rumahtangganya sendiri merupakan pemerintahan terendah di bawah camat. Desa bukanlah bawahan kecamatan, karena kecamatan merupakan bagian dari perangkat daerah kabupaten atau kota, dan desa bukan merupakan bagian dari perangkat daerah. Berbeda dengan kelurahan, desa memiliki hak mengatur wilayahnya lebih luas. Namun dalam perkembangannya, sebuah desa dapat diubah statusnya menjadi kelurahan.

Desa dibentuk atas prakarsa masyarakat dengan memperhatikan asal-usul desa dan kondisi sosial budaya masyarakat setempat yang ada. Pembentukan desa dapat berupa penggabungan beberapa desa, atau bagian desa yang bersandingan, atau pemekaran dari satu desa menjadi dua desa atau lebih, atau pembentukan desa di luar desa yang telah ada itu.

\section{B. METODE PELAKSANAAN}

Untuk mencapai tujuan yang diharapkan program KKN di Kecamatan Payaraman dilakukan dengan pemberdayaan perekonomian masyarakat melalui pembuatan inovasi pengemasan makanan khas atau penghasil utama desa.

Tabel I. Metode, Kegiatan JKEM dan keterlibatan mahasiswa

\begin{tabular}{|r|l|l|c|c|}
\hline NO & Metode & Kegiatan & JKEM & Volume \\
\hline 1. & $\begin{array}{l}\text { Penyuluhan } \\
\text { kewirausahaan }\end{array}$ & $\begin{array}{l}\text { Menyelenggarakan } \\
\text { penyuluhan } \\
\text { pentingnya } \\
\text { kewirausahaan. }\end{array}$ & $1 \times 150 "$ & 15 \\
\hline
\end{tabular}


Diterbitkan oleh Lembaga Pengabdian kepada Masyarakat Universitas Ahmad Dahlan Yogyakarta

\begin{tabular}{|l|l|l|c|c|}
\hline 2. & $\begin{array}{l}\text { Proses } \\
\text { pengemasan } \\
\text { makan }\end{array}$ & $\begin{array}{l}\text { Mempraktekkan proses } \\
\text { pengemasan makanan. }\end{array}$ & $2 \times 150 "$ & 15 \\
\hline
\end{tabular}

\section{HASIL, PEMBAHASAN DAN DAMPAK}

\section{Potensi Payaraman}

Payaraman adalah sebuah Kecamatan di Kabupaten Ogan Ilir, Sumatera Selatan, Indonesia. Kecamatan ini merupakan satu dari enam belas kecamatan yang ada di Kabupaten Ogan Ilir. Kecamatan Payaraman terbentuk sejak tahun 2006 berdasarkan Peraturan Daerah Kabupaten Ogan Ilir Nomor 22 Tahun 2005 yang merupakan hasil dari pemekaran Kecamatan Tanjung Batu. Kecamatan Payaraman memiliki potensi singkong dan nanas sebenanrnya. Namun lebih sering memanfaatkan dan memproduksi dari bahan dasar singkong. Kecamatan Payaraman ini mempunyai potensi produk makanan yang bahan dasarnya itu singkong, dari bahan itu bisa di olah menjadi kerupuk singkong dan kue breza brezer. Nama dari kue ini memang sangat unik jika di dengar orang awam karena dari namanya itu sangat unik dan penyebutannya juga sedikit susah. Namun tidak disangka jika kue itu terbuat dari bahan dasar singkong.

\section{Gambar Pelaksanaan kegiatan}

Gambar aktivitas saat pembuatan makanan yang akan dikemas dengan kreativitas yang unik.

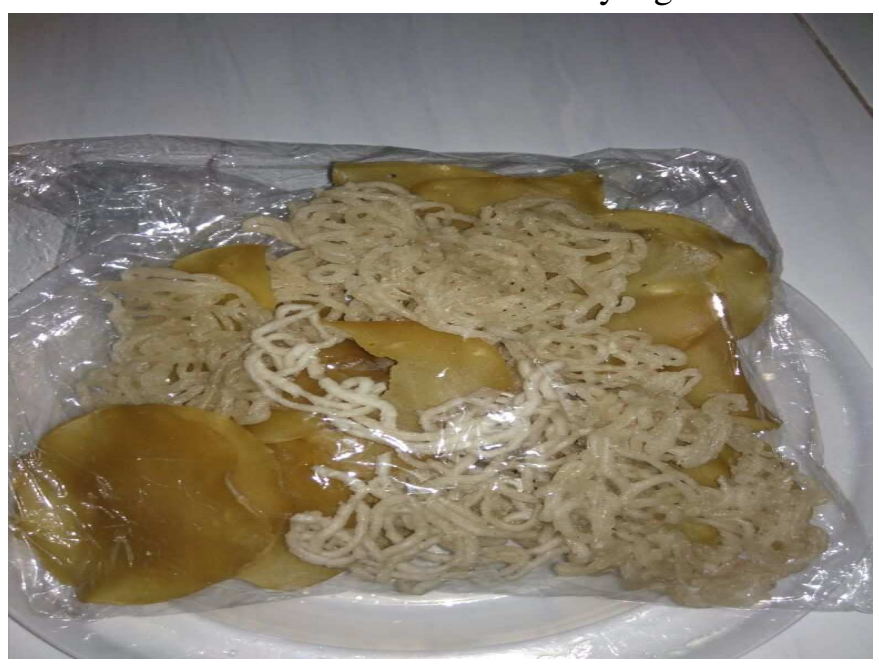

Pengemasan kue 


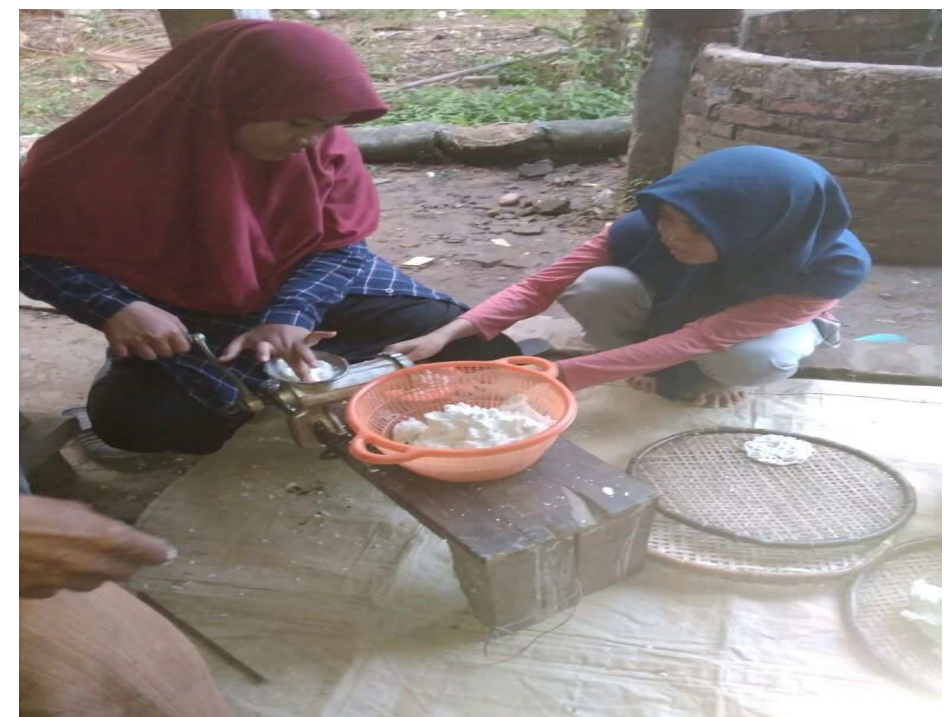

Pembuatan kerupuk yang selanjutnya akan dikemas.

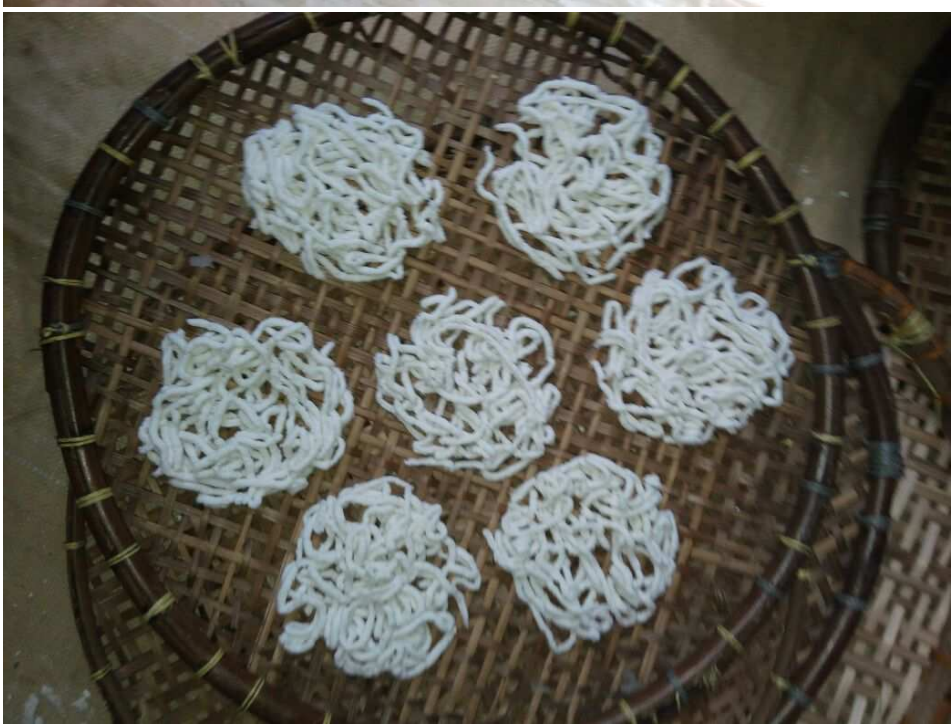

Kerupuk bahan dasar singkong yang akan di kemas

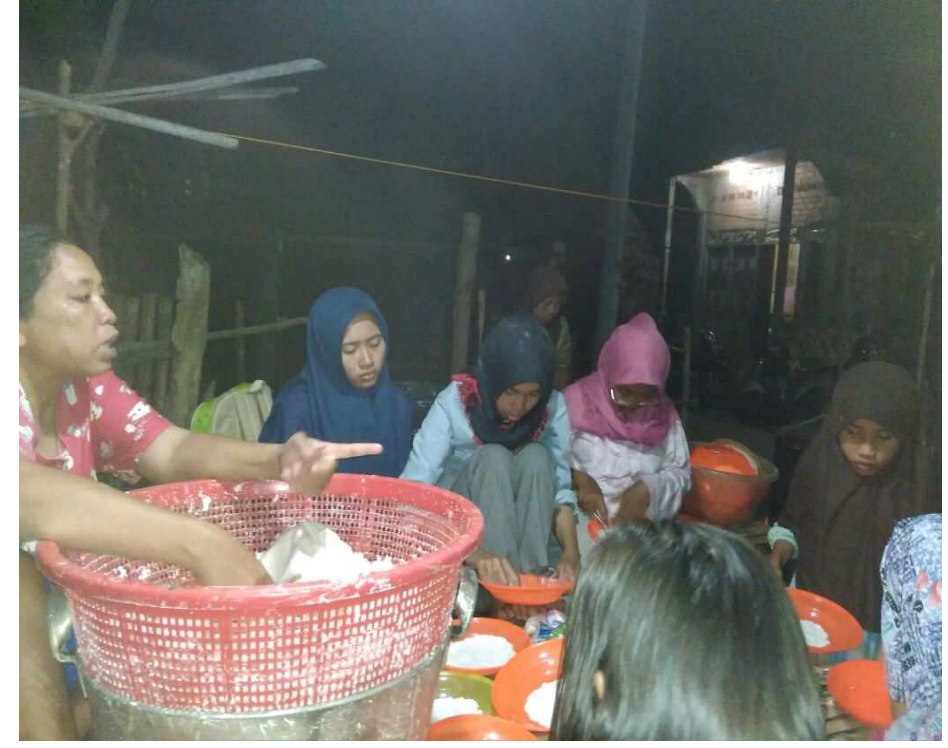

Peserta yang mengikuti penyuluhan 
Diterbitkan oleh Lembaga Pengabdian kepada Masyarakat

Universitas Ahmad Dahlan Yogyakarta

Dari gambar tersebut terlihat program KKN di Kecamatan Payaraman dapat terlaksana dengan partisipasi warga masyarakat yang lumayan bagus tanggapannya terhadap program yang sudah kita adakan. Dampak program kegiatan ini adalah 1) Mampu mengangkat perekonomian desa atau kecamatan. 2) Mampu menambah pendapatan perkapita untuk setiap keluarga. 3) Meningkatkan kesejakterahan perekonomian. 4) Mampu menjualkan produk ke luar Kecamatan.

\section{KESIMPULAN}

Program KKN dalam memberdayakan masyarakat khususnya di Kecamatan Payaraman ini untuk meningkatkan perekonomian atau pendapatan perkapita agar masyarakatnya bisa lebih inovasi dalam mengemas produknya. Maka dari itu untuk membentuk sumber daya manusia merupakan modal yang sangat penting dalam melakukan pembangunan. Keterkaitan masalah ini dengan pemberdayaan masyarakat sangat besar. Dampak pemberdayaan masyarakat adalah kemandirian masyarakat dalam mengatasi permasalahan mereka melalui prakarsa dan kreatifitas untuk meningkatkan kualitas hidup. Salah satu permasalahan di masyarakat yang ada di Kecamatan Payaraman Kabupaten Ogan Ilir, Sumatera Selatan ialah 1) Kurangnya kreativitas masyarakat dalam hal pengemasan makanan. 2) Kurangnya pengetahuan dalam mengembangkan produk yang ada. 3) Kurangnya pengetahuan dalam hal pemasaran makan. Metode yang dipakai dalam kegiatan inovasi pengemasan makanan yaitu 1) dengan mengadakan penyuluhan kewirausahaan dan 2) dengan proses pengemasan makanan. Dampak program kegiatan ini adalah 1) Mampu mengangkat perekonomian desa atau kecamatan. 2) Mampu menambah pendapatan perkapita untuk setiap keluarga. 3) Meningkatkan kesejakterahan perekonomian. 4) Mampu menjualkan produk ke luar Kecamatan.

\section{DAFTAR PUSTAKA}

Arifin Bustanul. 2003. Analisis Ekonomi Pertanian Indonesia. Penerbit Buku Kompas.

Jamasy Owin. 2004. "Keadilan, Pemberdayaan dan Penanggulangan Kemiskinan. Blantika Mizan.

Sjahrir dan Korten. 1988. Pembangunan Berdimensi Kerakyatan. Yayasan Obor Indonesia.

Syarief, R., S.Santausa, St.Ismayana B. 1989. Teknologi Pengemasan Pangan.Laboratorium Rekayasa Proses Pangan, PAU Pangan dan Gizi, IPB. 
